\title{
Agricultura Familiar:
} Caminhos para Apreender sua Diversidade ${ }^{1}$

Este texto tenta resgatar a metodologia de uma pesquisa desenvolvida com agricultores-suinocultores no sul do Brasil, especialmente no Paraná.

Entre estes agricultores predomina a agricultura familiar, herdeira do modelo de colônia de imigrantes que marcou tanto a feição social da região. A trilogia policultura-criação de suínos-trabalho familiar foi, ali, a base da expansão da fronteira agrícola e o fundamento da constituição da estrutura agrária local, apesar de sempre conviver, de forma mais ou menos próxima, com a concentração da terra, como em qualquer outra parte do país. Mesmo após a modernização da agricultura e da suinocultura, este segmento continua ali importante, apesar de substancialmente transformado.

Serão destacados, da mencionada pesquisa, principalmente as questões metodológicas e as conclusões relativas ao uso da mão de obra familiar nos estabelecimentos agrícolas, que é bastante importante (Tabela 1).

Para melhor caracterizar os agricultores pesquisados, elaborou-se uma tipologia a partir dos dados obtidos através da pesquisa por questionários. Sem apresentar os procedimentos metodológicos da pesquisa de $\mathrm{campo}^{2}$, aqui serão expostos os critérios utilizados para a elaboração da tipologia, que dividiu os 400 agricultores pesquisados em seis tipos, distribuídos e denominados conforme se vê no gráfico $\mathrm{n}^{\circ} 1$.

Antes de apresentar os critérios que levaram a esta distribuição, algumas questões de fundo sobre o estatuto desta tipologia e de seu papel no âmbito mais geral deste trabalho devem ser explicitadas.

Primeiramente, esta tipologia tem a pretensão de organizar de uma outra forma uma parcela dos dados levantados sobre os agricultores, de modo a avançar na sua compreensão, em relação ao que já se obteve neste sentido a partir do enunciado simples destes mesmos dados através de tabelas. No entanto, como qualquer elaboração desta natureza, tem seus pressupostos teórico-epistemológicos,

- ${ }^{1}$ Este texto resume questões analisadas em uma tese de doutorado intitulada Agriculteurs et agro- industries: stratégies, adaptations et conflits. Etude de cas au Paraná, Brésil, defendida na Université de

la Sorbonne Nouvelle-Paris III em maio de 1995. Limitou-se, aqui, a apresentar algumas das con-

- clusões finais a que se chegou e uma parcela restrita dos dados levantados.

- ${ }^{2}$ Estes procedimentos são discutidos em FERREIRA, op. cit., no item”Introdução". 
Tabela 1 - Força de trabalho utilizada nos estabelecimentos dos suinocultores pesquisados no Paraná

\begin{tabular}{|c|c|c|c|c|c|c|}
\hline \multirow{2}{*}{ Força de trabalho utilizada } & \multicolumn{2}{|c|}{ Integrados } & \multicolumn{2}{|c|}{ Não Integrados } & \multicolumn{2}{|c|}{ Total } \\
\hline & $N^{\circ}$ & $\%$ & $N^{\circ}$ & $\%$ & $N^{\circ}$ & $\%$ \\
\hline Exclusivamente Familiar & 138 & 48,2 & 47 & 41,6 & 185 & 46,2 \\
\hline Familiar + Assalariados temporários & 79 & 27,5 & 13 & 11,5 & 92 & 23,0 \\
\hline Familiar + Assalariados permanentes & 52 & 18,1 & 30 & 26,5 & 82 & 20,5 \\
\hline Familiar + Assalariados. tempor. e perman. & 7 & 2,4 & 7 & 6,2 & 14 & 3,5 \\
\hline Exclusivamente Assalariados & 11 & 3,8 & 16 & 14,2 & 27 & 6,8 \\
\hline TOTAL & 287 & 100,0 & 113 & 100,0 & 400 & 100,0 \\
\hline
\end{tabular}

Fonte: Amostra constituída por agricultores presentes nos Encontros Estaduais de Suinocultores do Paraná, realizados em julho de 1991 em Laranjeiras do Sul (Paraná) e em julho de 1993 em Medianeira (Paraná).

\section{Gráfico $n^{0} 1$}

Distribuição dos agricultores por tipo

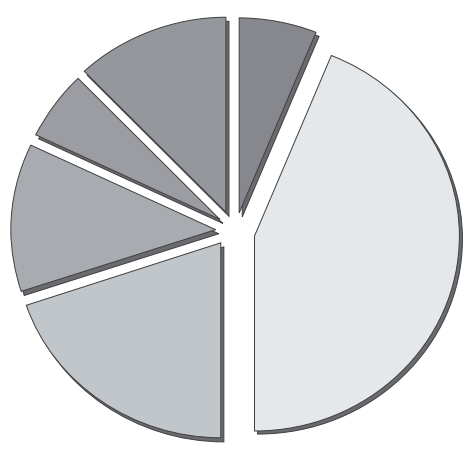

logo, mencionada: trata-se de tipos no sentido de tipos ideais de ações orientadas por determinados fins ou valores que os distinguem uns dos outros? Na presente tipologia, a concepção foi classificatória, não próxima a constituição de tipos, no sentido weberiano do conceito, e sim de uma construção de agrupamentos de agricultores a partir de algumas características das explorações e da organização da produção nelas.

É bastante comum esta forma de utilização da denominação tipo, só que é bem menos freqüente uma explicitação do seu real alcance nesta forma de utilização. Os resultados são, como se disse, classificatórios, mas as classes ou estratos, embora constituídos com a arbitrariedade intrínseca a este tipo de procedimento, podem tentar incorporar, pelo cruzamento de mais variáveis e pela sua qualificação por intermédio de outros dados disponíveis, um sentido sociológico que ultrapasse uma par-

por mais que sua pretensão se circunscreva a isto.

Um primeiro pressuposto é o de que a apreensão da realidade desta forma sincrônica e sintética (para não resvalar na dicotomia entre dados quantitativos equalitativos), tal como o foi a partir do levantamento por questionários curtos e fechados, tem sua validade e pode ser base para uma reconstrução destes dados que contribua para o entendimento da realidade em questão. Uma validade restrita, uma vez que as perguntas e a forma de resposta possível a este tipo de instrumento de pesquisa é necessariamente esquemático, não permitindo uma maior qualificação das informações e, portanto, limitando o alcance de qualquer classificação feita à partir delas. Para sanar este problema metodológico, outros instrumentos de pesquisa devem ser utilizados e, na medida do possível, o foram.

Um segundo pressuposto tem a ver como a própria concepção de que se dotou o instrumento metodológico da tipologia. Quando se fala em tipo, a tradição weberiana neste sentido deve ser, desde cela desta fortuidade da classificação e contribua para o entendimento das diversidades e/ou homogeneidades entre estes agricultores. Fala-se de tipos como se fala de agrupamentos de agricultores, embora o conceito de tipos seja mais adequado: pressupõe mais que uma classificação em grupos com certas características, indica que sempre se está falando de construções teóricas, que organizam e reconstruem a realidade sem pretender reproduzi-la.

Além destes pressupostos, é importante ressaltar que esta tipo- 
logia não se pretende central neste trabalho, mas, como já se disse, complementar como instrumento de entendimento dos agricultores estudados. Procurou não se construir para chegar a resultados já conhecidos ou desejados, embora não tenha certamente a pretensão de neutralidade. $\mathrm{O}$ que se quer salientar é seu caráter de instrumento de análise exploratória, complementar a outros, que fez seu caminho mostrando relações e indicando aspectos inesperados no início do trabalho. Para preservar este caráter, optou-se por uma classificação que não conduzisse muito rapidamente a a prioris teóricos e que salientasse elementos classificatórios tomados como importantes, como o foram a área dos estabelecimentos e a escala da produção, como pode ser ver pelas denominações dos tipos (Gráfico ${ }^{\circ}$ $1)^{3}$.

Um outro aspecto a assinalar é que não se pode pretender a representatividade destes dados, no sentido estatístico do termo, dadas a forma de levantamento utilizada. Fala-se em amostra para designar estes agricultores como parte de um todo maior, mas não se pôde precisar em que nível são representativos. Isto posto, os tipos construídos a partir destes dados não podem pretender tipificar os agricultores-suinocultores do Estado, muito menos do país. No entanto, outras fontes (por exemplo, o cadastramento anual da Associação Paranaense de Suinocultores) e, principalmente, a visão da realidade que têm alguns técnicos ou agricultores que atuam no âmbito desta atividade parecem corroborar, a grosso modo, estes dados, o que valida a tipologia ao menos como indicativa desta realidade mais geral.

Quanto aos critérios de sua construção, cabe também lembrar alguns critérios concernentes ao questionário em si e explicitar os que têm a ver especificamente com a presente tipologia.

Cada questionário corresponde a um agricultor e a um estabelecimento. Por isto, fala-se indistintamente de agriculturas ou exploração, num total de 400 .

Os questionários foram aplicados em dois Encontros Estaduais de Suinocultores do Estado do Paraná. Aqueles com respostas em branco nas variáveis básicas de classificação utilizadas não foram considerados para construção da tipologia, (o que totalizou em torno de $15 \%$ de descarte do total das amostras de que se dispunha). Portanto, os 400 incluídos na tipologia foram os que tinham todas as questões básicas respondidas.

As variáveis básicas utilizadas para a classificação foram:

a) tamanho do estabelecimento (em estratos de hectares, seguindo os grupos de área do censo agro- pecuário brasileiro). O tamanho é relativo à superfície total do estabelecimento e não à área explorável.

b) escala de produção na suinocultura (em estratos por número de matrizes, no caso dos agricultores de ciclo completo, dos iniciadores e dos criadores de matrizes e em estratos por número de porcos, no caso dos terminadores).

c) força de trabalho utilizada nas explorações: estabelecimentos que só utilizam mão de obra familiar; os que utilizam mão de obra familiar e assalariados temporários; estabelecimentos que utilizam mão de obra familiar e assalariados permanentes; os que utilizam mão de obra familiar e assalariados em geral, tanto temporários como permanentes; estabelecimentos cujo trabalho é exclusivamente feito por trabalhadores assalariados.

Cabe ressaltar que o instrumento de coleta destes dados não permitia uma qualificação dos conceitos de mão de obra familiar ou de todas as formas de assalariamento possíveis. A pergunta era genérica e não pode mensurar em horas durante um período dado o emprego de assalariados, como também não permite entender que tipo de relações se desenvolvem sob o rótulo de "mão de obra familiar" ou que tipo de papel a família e o assalariamento desempenham no âmbito mais geral de reprodução social destes estabelecimentos. 
Todas as questões sobre força de trabalho são densas em significados teóricos dentro da sociologia rural e por isto o alcance de cada análise deve ser bem precisado.

No presente caso, os dados sobre mão de obra foram tomadas, portanto, como informações sincrônicas e indicativas. Foram úteis para demonstrar certas relações e, com o auxílio de outras fontes, foram importantes para mostrar quem são os agricultores integrados e o papel que para eles têm a família como força de trabalho mas também como referência fundamental de suas estratégias quanto à contratualização.

d) contratualização do estabelecimento para a criação de suínos: estabelecimentos, portanto, integrados e não integrados. Entre os não integrados há os que já o foram e os que nunca tiveram contratos com indústrias agro-alimentares para o fornecimento de suínos.

Como variável complementar mas não classificatória, incluiu-se a modalidade de criação praticada pelos agricultores: ciclo completo ou especializados (iniciadores e terminadores) e criadores de matrizes.

- As quatro variáveis foram cruzadas simultaneamente ${ }^{4}$ para uma análise preliminar das interrelações possíveis entre elas. A seguir, foi utilizada a variá- vel escala de produção como a primeira classificatória e, a partir daí, realizou-se uma segunda classificação por seu cruzamento com a área dos estabelecimentos. Acrescentaram-se as variáveis mão de obra e existência ou não de contrato de integração para o cruzamento final que deu origem à tipologia.

- uso de porcentagens, quando indevidas (em se tratando de parcelas de valores globais inferiores a 100), foi restringido ao mínimo. Neste caso, têm caráter estritamente demonstrativo e visa permitir algumas comparações entre os tipos.

A tabela 2 traz a síntese de todos dos dados que correspondem aos tipos.

Sem entrar nos detalhes dos dados acima apresentados, podese ter uma idéia comparativa entre os tipos de agricultores pelos resumos abaixo:

Caracterização-resumo dos produtores de tipo 1

- Produtores de ciclo completo, com alguns terminadores.

- Produção numa escala de menos de 5 matrizes (número modal de 2,5 matrizes); no caso dos terminadores, com de menos de 150 suínos terminados por lote (número modal de 99,5 suínos)

- Produtores não integrados (73 $\%)$

- Área do estabelecimento de menos de 20 ha (área modal de 9,7 ha).

- Produtores que só utilizam mão de obra familiar

Neste tipo de estabelecimento, a suinocultura é uma atividade entre outras destes estabelecimentos, complementar em sistemas agrícolas diversificados, importante para otimizar a mão de obra disponível e para gerar adicionais de renda para os agricultores.

Caracterização-resumo dos produtores de tipo 2

- Produtores sobretudo de ciclo completo mas também, em menor grau, de terminadores, de iniciadores e de criadores de matrizes

- Produção numa escala de mais de 5 matrizes e menos de 20 (número modal de 11,3 matrizes); os terminadores produzindo numa escala de 150 à menor de 500 suínos por lote (número modal de 221,3 suínos terminados por lote)

- Produtores integrados $(84,5 \%)$

- Área do estabelecimento entre

- ${ }^{4}$ O programa File Maker Pro (Claris Corporation) foi utilizado para constituir a base de dados - e para o cruzamento simultâneo das variáveis. O programa Excel foi utilizado para as tabelas e - gráficos. 
10 à menos de 50 ha (área modal de 22,5 ha)

- Produtores que empregam no estabelecimento exclusivamente mão de obra familiar (caso majoritário - perto de $60 \%$ dos estabelecimentos), ou a mão de obra familiar com assalariados temporários

A suinocultura é uma atividade importante nos estabelecimentos dos suinocultores deste tipo, entre outras atividades de cultura ou criação, representando uma complementação de renda e uma forma de otimização do trabalho familiar para a maior parte deles.

Considerando-se o fato de que este tipo concentra quase a metade do total dos suinocultores e mais da metade dos suinocultores pesquisados, pode-se aventar a hipótese de que este perfil corresponde ao do suinocultor típico e do integrado típico na suinocultura.

\section{Caracterização-resumo do tipo 3}

- Produtores sobretudo de ciclo completo, mas reunindo tam- bém iniciadores e criadores de matrizes e minoritariamente terminadores.

- Produção numa escala entre 20 matrizes e menos de 50 (número modal de 34,9 matrizes) ou de 500 à menos de 1000 suínos por lote (número modal de 750 suínos terminados por lote)

- Produtores integrados $(78 \%)$

- Área do estabelecimento entre 10 e menos de 50 ha (área modal de 24,5 ha)

Tabela 2 - Distribuição geral dos agricultores por tipo

\begin{tabular}{|c|c|c|c|c|c|c|c|c|c|c|c|c|c|c|c|c|c|c|}
\hline \multirow[t]{2}{*}{ TIPO } & \multirow{2}{*}{$\begin{array}{c}\text { Número } \\
\text { de Matrizes } \\
\left(C, I, M^{*}\right)\end{array}$} & \multirow{2}{*}{$\begin{array}{l}\text { Número } \\
\text { de Suínos } \\
\left(T^{*}\right)\end{array}$} & \multirow{2}{*}{ Área (Ha.) } & \multirow[t]{2}{*}{$N^{\circ}$} & \multirow[t]{2}{*}{$\%$} & \multicolumn{4}{|c|}{$\begin{array}{l}\text { Situação quanto } \\
\text { a contrato (suinocultura) }\end{array}$} & \multicolumn{5}{|c|}{$\begin{array}{l}\text { Mão-de-obra utilizada } \\
\text { (no estabelecimento) }\end{array}$} & \multicolumn{4}{|c|}{ Modalidade de criação } \\
\hline & & & & & & Integ. & $\%$ & Não & $\%$ & $M F^{* *}$ & MFT $^{* *}$ & MFP** & MFTP $* *$ & Só $E^{* *}$ & $c^{*}$ & $l^{*}$ & $T^{*}$ & $M^{*}$ \\
\hline 1 & $1<5$ & $<150$ & $\begin{array}{c}1<5 \\
5<10 \\
10<20\end{array}$ & 26 & 6,5 & 7 & 2,5 & 19 & 17 & 22 & 4 & 0 & 0 & 0 & 23 & 0 & 3 & 0 \\
\hline 2 & $\begin{array}{c}5<10 \\
10<20\end{array}$ & $150<500$ & $\begin{array}{c}0<5 \\
5<10 \\
10<20 \\
20<50\end{array}$ & 175 & 44 & 148 & 52 & 27 & 24 & 101 & 49 & 16 & 4 & 5 & 123 & 24 & 16 & 12 \\
\hline 3 & $20<50$ & $500<1.000$ & $\begin{array}{c}0<5 \\
5<10 \\
10<20 \\
20<50\end{array}$ & 78 & 19,5 & 61 & 21 & 17 & 15 & 30 & 21 & 20 & 2 & 5 & 51 & 12 & 6 & 9 \\
\hline 6 & $1<10$ & $<150$ & $\begin{array}{c}20<50 \\
50<100 \\
100<200\end{array}$ & 48 & 12 & 26 & 9 & 22 & 19,5 & 23 & 14 & 4 & 2 & 5 & 21 & 15 & 9 & 3 \\
\hline$T$ & & & & 400 & 100 & 287 & 100 & 113 & 100 & 185 & 93 & 81 & 14 & 27 & 263 & 62 & 34 & 41 \\
\hline
\end{tabular}

${ }^{*} \mathrm{C}$ : Suinocultores de Ciclo Completo.

I: Iniciadores.

T: Terminadores.

M: Criadores de Matrizes.

${ }^{*} M$ MF: Estabelecimentos que só uttilizam mão-de-obra familiar

MFT: Estabelecimentos que utilizam mão-de-obra familiar e mão-de-obra temporária.

MFP: Estabelecimentos que utilizam mão-de-obra familiar e mão-de-obra permanente.

MFTP: Estabelecimentos que utilizam mão-de-obra familiar, mão-de-obra temporária e mão-de-obra permanente.

Só E: Estabelecimentos que utilizam somente empregados. 
- Produtores que trabalham com mão de obra familiar mas sobretudo combinada com o emprego de mão de obra externa temporária ou permanente.

A suinocultura é uma atividade muito importante nestes estabelecimentos, considerando-se o número de matrizes, mas combinada com outras atividades de cultura ou criação.

\section{Caracterização-resumo do tipo 4}

- Produtores de ciclo completo, criadores de matrizes e iniciadores.

- Produção numa escala de 50 a menos de 100 matrizes (número modal de 121,3 matrizes)

- Produtores 50\% integrados.

- Área do estabelecimento com mais de 20 até menos de 200 ha (área modal de 91,7 ha)

- Produtores que conduzem seus estabelecimento com emprego de mão de obra assalariada, mas sobretudo combinada ao trabalho de membros da família. A contratação de assalariados é predominante, para atendimento da criação de suínos e para outras atividades do estabelecimento.

A suinocultura é uma atividade prioritária no estabelecimento des de culturas ou criação também relevantes.

\section{Caracterização-resumo do tipo 5}

- Produtores de ciclo completo, criadores de matrizes e iniciadores.

- Produção numa escala entre 50 matrizes e menos de 200 (número modal de 66 matrizes).

- Produtores integrados e não integrados, com predominância dos integrados.

- Área dos estabelecimentos com menos de 20 ha (área modal de 10,3 ha)

- Produtores que conduzem seus estabelecimento com emprego de mão de obra assalariada, mas sobretudo combinada ao trabalho de membros da família. A contratação de assalariados é predominante, para atendimento da criação de suínos.

A suinocultura é a atividade prioritária do estabelecimento, considerando a relação $\mathrm{n}^{\circ}$ de matrizes / área.

\section{Caracterização-resumo do tipo 6}

- Produtores de ciclo completo, iniciadores e terminadores.

- Produção numa escala de menos de 5 matrizes (número modal de 3,8 matrizes) ou menos de 150 suínos por lote, no caso dos terminadores (número modal de 132,8 suínos terminados por lote).
- Produtores 50\% integrados.

- Área do estabelecimento com mais de 20 até menos de 200 ha (área modal de 80,2 ha).

- Produtores que conduzem suas atividades com emprego de mão de obra familiar, mas sobretudo combinada com assalariados temporários para os trabalhos de lavoura.

A suinocultura é marginal nestes estabelecimentos, considerando a escala pequena de produção e a área significativa.

Uma conclusão geral desta tipologia, nos seus aspectos mais gerais, é de que a integração envolve todos os tipos de agricultores como sua forma preferencial de inserção na atividade da suinocultura. Falar em integrados é, portanto, tratar de um segmento bastante heterogêneo de agricultores, cuja identidade é circunscrita a um conjunto de relações com as indústrias, nas quais suas diferenças certamente influem. Por outro lado, há integrados que se aproximam uns dos outros por elementos de identidade dados por parâmetros a princípio oriundos de suas inserções de ordem sócio-econômica mais geral, entre as quais as levantadas como elementos de diferenciação dos tipos - e outras desta ordem e de ordem cultural, além, obviamente, de suas inserções associativistas e políticas.

No que interessa aos objetivos deste trabalho, vão ser analisadas as constatações que esta tipologia 
permite demonstrar no que concerne especificamente à mão de obra utilizada nos estabelecimentos agrícolas.

A importância da força de trabalho familiar nos estabelecimentos analisados foi bem demonstrada na tipologia, como se vê no Gráfico n ${ }^{\circ} 2$.

Em todos os tipos, é majoritário o emprego de força de trabalho familiar, combinado ou não com trabalhadores externos à família: mais de $90 \%$ dos agricultores utilizam a mão de obra familiar em seus estabelecimentos, nas culturas e na criação, seja qual for sua forma de inserção na organização da produção e os mecanismos de recompensa ou pagamento utilizados. Menos de $7 \%$ dos estabelecimentos utilizam só mão de obra assalariada. Segundo estes dados, mesmo os estabelecimentos de grandes produtores afirmam utilizar o tra- balho familiar como mão de obra importante, embora neste caso não como força de trabalho majoritária.

Os estabelecimentos que empregam somente a família como força de trabalho são amplamente predominantes no tipo 1 e no tipo 2. Nos outros tipos, como já vimos, a mão de obra externa predomina mas sobretudo em combinação com o trabalho familiar.

Há uma evidente correlação entre aumento de escala de produção e área e aumento de utilização de mão de obra externa à família. No entanto, a presença importante da família em todos os tipos, assim como a presença de mão de obra assalariada também em todos os tipos mostra que há outros imperativos, não oriundos apenas de fatores que poderíamos denominar de estritamente ligados à escala de capitaliza-

Gráfico $n^{\circ} 2$

Mão-de-obra utilizada, segundo os tipos de agricultores pesquisados



ção cuja compreensão é necessária para o entendimento das formas de trabalho adotadas nestes estabelecimentos.

Uma análise complementar à realizada para construção desta tipologia, a partir de entrevistas com uma parcela dos agricultores que responderam ao questionário que foi base dela, permitiu responder a algumas das lacunas que um instrumento deste tipo inevitavelmente não preenche.

O que parece, no entanto, relevante, do ponto de vista metodológico, é que os dados subsequentes, levantados a partir destas entrevistas, corroboraram a tipologia em termos do que se poderia chamar de relações pertinentes que a teoria sobre agricultores e camponeses nos permite aventar como hipóteses de compreensão deste segmento social. Ou seja, foi possível constatar que os tipos construídos por dados sincrônicos e classificatórios têm validade e consistência na explicação de outras diferenças entre os agricultores: no que tange às suas estratégias de contratualização, no que diz respeito às concepções mais gerais sobre seus objetivos no métier de agricultor, como se verá a seguir. Ao mesmo tempo, os dados mais aprofundados das entrevistas permitiram qualificar melhor a tipologia e mostrar suas imprecisões, principalmente ao tornar menos fluído o item "força de trabalho familiar" precisando seus múltiplos significados para os agricultores que afirmam utilizá-la. 


\section{A Contratualização como Estratégia ${ }^{5}$}

A maior parte dos agricultores que atuam na atividade da suinocultura no Paraná é contratualizada às indústrias, o que também é verdadeiro - não no mesmo nível para os outros Estados do sul do país.

O que leva os agricultores a procurarem ou aceitarem este contrato de produção? Para responder a esta pergunta, devem ser ponderados elementos de ordem mais geral que constróem o campo das escolhas individuais possíveis, dentre elas a de se integrar.

A nível geral da estruturação da rede agro-alimentar, a contratualização aparece como um elemento da sua dinâmica, ligando os diferentes atores produtivos desta rede entre si e com a economia mais ampla.

No caso da relação dos agricultores com a industrias, esta dinâmica de se traduz numa relação que implica no crescente controle industrial sobre a qualidade do produto demandada aos criadores, na forma de produzi-lo e na sua comercialização. É assim que o agricultor se integra neste rede agroalimentar como fornecedor de matéria prima para o processamento industrial e como consumidor de insumos e produtos industrializados que a nova forma de produzir lhe impõe.
É dentro deste quadro geral que se inscrevem os elementos mais gerais desta decisão de contratualizar-se que, na sua construção imediata, se faz a nível individual e familiar.

Sem entrar, no momento, na análise das conjunturas diferentes da contratualização no Paraná que vão ter seu papel na construção do campo de possibilidades para exercício das estratégias dos agricultores, vamos aqui verificar como tais estratégias se traduzem em motivos que levam à contratualização.

A diferença entre as conjunturas distintas da história da integração não muda, entre os integrados, as razões básicas que percebem como motivadoras da busca do contrato: poder prescindir de financiamento bancário para capital de giro e ter o mercado assegurado para seu produto. A indústria integradora fornece os insumos e a ração e os desconta, na maior parte destes, do preço a ser pago pelo produto. Se o preço é motivo de conflito, não é menos verdade que este financiamento da atividade produtiva é fundamental para os agricultores. No caso das culturas, eles têm de recorrer a bancos, o que nem sempre é fácil para o produtor. A garantia de venda é outro ponto importante para viabilização da atividade mas considerada menos crucial que a primeira razão pelos agricultores.

Os outros motivos assinalados trazem mais a particularidade da conjuntura de integração: os integrados de após 80 mostram a integração como a única alternativa possível para os pequenos produtores, o que não é assinalado pelos integrados dos primeiros períodos; a facilidade de contar com a assistência técnica da empresa é apontada pelos agricultores mais novos na integração; e o fato de ter o chiqueiro financiado é assinalado por um agricultor dos primeiros períodos, já que, mesmo se raro na conjuntura inicial da integração, depois tornou-se ainda mais difícil de se obter.

Os motivos verbalizados que conduzem à integração não diferem entre os diferentes tipos de agricultores no que diz respeito às principais razões alegadas. No entanto, os micro produtores se restringem à questão do financiamento da atividade pelas indústrias; os pequenos produtores alegam igualmente este motivo e a garantia de mercado, além de serem os que vêem a integração como única alternativa para pequenos produtores; os médios praticamente se restringem às duas razões majoritárias; os grandes produtores (com áreas grandes ou pequenas) também; os pequenos produtores com áreas grandes assinalam igualmente os dois motivos principais mas referem-se às vantagens da assistência técnica.

Para os micro-produtores, a falta de recursos para custear a criação 
dentro dos padrões mínimos da suinocultura modernizada é uma questão incontornável, dados os rendimentos pouco significativo de suas culturas em pequena escala. Os mais antigos foram atraídos pelo fornecimento da ração sem juros. Os mais novos reconhecem que os juros sobre a ração são para eles altos mas o fato de não ter a desembolsar dinheiro para compras de insumos é um aspecto que consideraram fundamental na integração.

Os pequenos e médios produtores assinalam com ênfase as duas razões principais. Entre os primeiros, alguns explicam a integração como uma contingência para os pequenos produtores, dada sua situação de carência de recursos e difícil acesso a crédito e também para as dificuldades de venda no chamado mercado livre em épocas de crise da atividade. É interessante notar que estão entre estes os agricultores que fizeram uma análise mais geral de sua inserção numa categoria à parte entre os suinocultores- a dos pequenos produtores.

Para os grandes produtores, há uma diferença interessante entre os do tipo 4 (grande produção e grande área) e os do tipo 5 (grande produção e pequena área). Ambos assinalam que a integração é uma garantia, uma segurança para o grande produtor porque assegura mercados e insumos, re- solvem o problema do capital de giro e por estes motivos explicam estarem integrados. Mas a ênfase dos segundos é sobre o fornecimento da ração e do milho, já que para eles, praticamente dependentes de compras externas destes produtos e grandes demandistas deles, a insegurança da falta especialmente do milho e a garantia que neste sentido têm na integração são ressaltados.

Para os produtores com pequena produção e grandes áreas, os mesmos motivos são assinalados mas é entre eles que aparece a menção ao fornecimento de assistência técnica pelas indústrias. Valorizam este aspecto por não terem condições nem conhecimento para desenvolverem a suinocultura modernizada. Neste sentido, é útil terem orientações que basta seguir, como exemplifica a seguinte fala de uma agricultor deste tipo:

\footnotetext{
"Temos tradição na suinocultura mas não no trato atual porque sempre fizemos mais força na lavoura. Quando resolvemos integrar é porque achamos que era mais seguro para tudo, mesmo para cuidar dos porcos bem porque bastava seguir as orientações do técnico, que era a empresa nos mandava”. (Entrevista n ${ }^{\circ} 57,1993$ )
}

Entre todos os tipos de agricultores mas sobretudo entre os micro - é o caso de todos os agricultores deste tipo entrevistados - e os pequenos, há um discurso que antecede a explicitação dos motivos e que se poderia denominar de motivos de atração ${ }^{6}$ : há a colocação de que foram procurados e convencidos por técnicos ou representantes comerciais das indústrias para se decidirem a fazer os contratos, num processo que identificam seja como uma sedução - que depois pode ter se mostrado enganadora - seja como uma valorização deles enquanto agricultores, uma sorte de escolha pelo seu próprio valor. Neste último caso, a sedução também é mencionada mas aparece como uma conseqüência natural da valorização. A sedução se traduz pela ênfase nas vantagens da integração, justamente nos dois pontos mais problemáticos da atividade para os agricultores: falta de capital de giro e insegurança na venda.

É corrente o fato de que os agentes das indústrias exercem esta construção da motivação a partir das vantagens que sabem serem as principais para os agricultores, mas não deixa de ser significativo o fato de que esta percepção seja mais peculiar entre os produtores de menor escala, de menor terra - os micro-produtores e uma parte significativa dos pequenos. Pode-se supor que se trata de uma estratégia para transferir a responsabilidade da decisão para os atores mais fortes da relação mas ao mesmo tempo pode indicar uma percepção de sua importância diante destes mesmos atores - afinal, eles, os das indústrias, precisaram conven- 
cer um agricultor para participar do seu negócio. Como exemplos, veja-se os dois trechos de falas de agricultores que se seguem:

"Ele (o representante comercial da Sadia) me procurou para dizer das vantagens de integrar com a Sadia, da ração para pagar com porco, de não ter de se preocupar com a venda. Veio duas vezes aqui em casa e disse que só insistia porque eu era zeloso. Daí pensei que isto resolvia meu problema... Mas na verdade hoje acho que o juro zera tudo"(Entrevista $n^{\circ}$ 62, julho de 1993)

"O técnico da cooperativa disse para o pai que nós cuidamos bem, que se tivesse integrado não se incomodava com dinheiro para o trato. Eles não pegam mais muita gente e disse que nós era um caso à parte porque tinha honestidade e zelo... resolvemos então fazer integrado porque senão não dava para aumentar”(Entrevista $n^{\circ} 56, \mathrm{ju}$ lho de 1993).

As justificativas sobre a escolha da empresa integrante incorporam este elemento de agenciamento de uma empresa específica, geralmente a que tem abatedouro mais próximo do estabelecimento. Mas há também outros elementos. Alguns como contingência - por exemplo o fato de que na época em que o agricultor começou a integração a
Sadia ser a única que trabalhava com este esquema na região. Aparece como contingência mas, na verdade não o é, o fato do agricultor já ser associado da cooperativa para comercialização de cereais. Para alguns agricultores isto acarreta com muita freqüência uma incitação à integração por parte dos técnicos da cooperativa. Neste caso, há também uma questão que é colocada como moral e que é explorada pelos dirigentes e membros mais ativos da cooperativa: "Dizemos sempre para o agricultor: porque fazer integração com uma empresa se a nossa cooperativa também faz e aqui estamos trabalhando para nós mesmos?"7

Outros elementos apontados como motivadores da escolha da empresa valorizam as vantagens: a solidez da Sadia é mencionada, contrapondo-a a algumas grandes cooperativas que tiveram sérios problemas no país, prejudicando os agricultores filiados; as menores exigências que uma ou outra indústria fazia à época em que se integrou, especialmente quanto a instalações ou mesmo quanto ao trato dos animais; e, finalmente, eventuais vantagens de diferentes tipos como ter acesso a insumos de melhor qualidade ou ter uma assistência técnica considerada melhor.

Em toda sua argumentação, tanto para decidir-se pela contratualização como para escolha da empresa, os agricultores mostram a construção de uma estratégia que tem por objetivo reproduzir ou alcançar fins valorizados por eles como relevantes: segurança, lucratividade, menores investimentos ou maior qualidade. Não desconhecem, em geral, a contingência desta estratégia mas valorizam a liberdade de sua decisão, o que se repete em outras questões sobre as quais foram incitados a refletir.

\section{Os Estabelecimentos dos Agri- cultores Integrados: Mão-de- obra Utilizada, Organização do Trabalho e Gestão ${ }^{8}$}

As unidades agrícolas dos integrados entrevistados têm, na sua maioria, um razoável nível de diversificação. Predomina a combinação de três culturas consideradas importantes para a exploração como milho-soja e mais uma cultura (trigo, feijão, fumo) mas também é significativa a combinação de duas culturas - o milho com uma outra (soja, trigo, feijão, fumo, laranja, mandioca). Há, como se viu, estabelecimentos que só plantam milho mas não são predominantes.

Em quase todos estabelecimentos dos agricultores entrevistados,

$\ldots \ldots \ldots \ldots$

- ${ }^{7}$ Entrevista com agroindústrias n 6, junho de 1993.

- ${ }^{8}$ As análises feitas neste item foram baseadas especialmente nas 67 entrevistas realizadas com inte- grados e eventualmente entrevistas com outros agentes sociais envolvidos com a questão da suino-

- cultura e da integração. Incorporaram, também, dados dos questionários realizados em Medianei-

- ra, no Encontro Estadual de Suinocultores do Estado do Paraná, em 1993. Neste último caso, a - fonte estará indicada nas tabelas respectivas. 
(67 entrevistas), o leite para autosubsistência está presente, assim como os habituais produtos chamados de subsistência- horta, galinhas, frutas, que podem ter uso também na criação, mas de maneira secundária (o soro do leite pode ser misturada à ração, alguns legumes também). O plantio de outros produtos de lavoura com finalidade básica de subsistência (como o feijão, o arroz, a mandioca) é menos presente, o que é explicado como fruto de falta de algum fator - terra, mão de obra e seu corolário, a saber, a disponibilidade de tempo. Por parte da alguns agricultores, sobretudo entre os micro e pequenos produtores mas também entre os médios, esta sensação de falta prevalece na explicação da ausência de mais plantios deste tipo. Para outros, como é o caso geral para os grandes produtores, a questão foi desconsiderada - o que não é sem significado-ou os argumentos repetiramse em relação ao dos primeiros mas no sentido de ressaltar que não compensa investir em produtos que se pode comprar para aprovisionamento com facilidade.

Encontram-se poucos casos de agricultores que não plantam praticamente nada para subsistência entre os que se classificou como do tipo 4 (grandes produtores) e entre os médios produtores. A justificativa é a falta de mão de obra ou tempo para levá-los a termo. São agricultores mais capitalizados, que contratam mão de obra para o que consideram rentável, trabalham uma parte do tempo na gestão e outra nas atividades mais le- ves da lavouras (com máquinas) e no trato da criação, que tem filhos estudando e cuja mulher desligouse da produção tradicionalmente dita doméstica e que era o cerne das atividades típicas de subsistência.

Um outro aspecto destes estabelecimentos é a condição do produtor que é o seu responsável: são praticamente todos proprietários da terra e são eles mesmos que são os integrados na suinocultura. É quase inevitável no Brasil que o proprietário da terra seja o contratado, porque isto tem sido uma exigência que a maioria das empresas impõe para selecionar seus integrados.

Já se viu reiteradamente que os estabelecimentos dos suinocultores integrados são tocados majoritariamente pela força de trabalho familiar, com ou sem a intervenção de mão de obra externa. Nas entrevistas isto se confirma e se qualifica melhor. Ali confirma sequer a utilização da mão de obra familiar ou externa depende principalmente mas não apenas do aumento da escala de produção ou de uma diversificação produtiva importante no estabelecimento. Um fator importante para a determinação da força de trabalho utilizada é a disponibilidade de mão de obra conforme o ciclo biológico-social da família: filhos pequenos, filhos ausentes e pais mais velhos são os casos mais freqüentes.

Depende também do número de pessoas da família de que se pode dispor de forma habitual, da disponibilidade de outras formas de trabalho, como poder ou não trocar de dias entre vizinhos ou contar com a ajuda eventual dos filhos ausentes nos momentos de pique das culturas.

Assim, a falta de mão de obra familiar, pelo fato dos filhos serem pequenos, força o agricultor a contratar empregado permanente e a buscar a ajuda de vizinhos para trocar dias. O fato de pagar um empregado pode ser para ele ao mesmo tempo um requisito de viabilização da exploração e um limite para sua capitalização, como se pode perceber pela resposta de uma agricultor:

\footnotetext{
"Eu tenho de ter empregado porque os filhos são pequenos, a mulher não pode ajudar. Pago porcentagem porque não dá para pagar salário e fico com menos, mas não tem jeito... Para quebra do milho eu troco dias com os vizinhos...Quando crescerem [os filhos] vão ter estudo mas daí podem ajudar e eu não conto em ter empregado, só se tiver sobrando para poder crescer mais"(Entrevista $n^{\circ}$ 61, julho de 1993).
}

Colocando a questão de forma inversa, também a capitalização maior do estabelecimento não exclui o emprego exclusivo de mão de obra familiar: entre os "exclusivamente familiares" encontramse agricultores mais capitalizados (os que estariam incluídos no tipo 4 e 5 da tipologia proposta).

Entre os agricultores que decla列

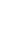

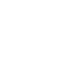


ram só trabalhar com a família há aqueles em que o vínculo familiar é a forma de agenciamento da mão de obra mas não o elemento estruturante da relação de trabalho que não deixa de ser o assalariamento, combinado normalmente com o pagamento em produto. Nos dois casos registrados, os produtores exerciam mais um trabalho de gestão embora ainda trabalhassem com a criação, seu(s) filho(s) ainda solteiro(s) trabalhavam na propriedade em tempo parcial e havia o concurso de parentes - um ou dois - com pagamento em porcentagem e salário. Um destes produtores se referiu a estes parentes de uma forma peculiar que mostra a ambigüidade desta relação:

\footnotetext{
"Aqui não temos empregados, só a família trabalha...Eu cuido de tudo, mais administro porque senão não dá dinheiro mas os porcos cuido com a mulher e o filho. Meu irmão e meus sobrinhos que moram perto cuidam das culturas." [O filho e os outros ganham como?]... "O filho só ajuda, tem de estudar. O peão tem parte da colheita da soja e os peãozinhos ${ }^{9}$ eu pago quando vêm.” [Quem são estes - o peão e os peãozinhos?] [risos] "O irmão e os sobrinhos.”. Entrevista n ${ }^{\circ} 37$, junho de 1991.
}

A denominação dada aos parentes, mesmo se no tom de brincadeira, revela a relação de trabalho que há entre eles e contradiz sua afirmação inicial ("aqui não temos empregados”) porque a representação do trabalho dos parentes é ambígua para este agricultor. Este e um outro agricultor que também tem este tipo de relação com parentes aparece sob rubrica"trabalho exclusivamente familiar" porque é o laço familiar que recruta o trabalho - o que não explica a forma de inserção estes trabalhadores no âmbito do estabelecimento. Perceber esta forma de assalariamento não implica, no entanto, em igualar a sociabilidade ali construída com a relação típica entre patrão e empregado. Nestes dois casos mencionados, os agricultores são capitalizados e estariam classificados respectivamente no tipo 4 e 6 (grande produtor, pequeno produtor/grande área).

Mas na maioria dos casos aqui registrados, a força de trabalho exclusivamente familiar é composta por um grupo de membros da família nuclear, com pouca divisão interna do trabalho, fora a especificidade do trabalho da esposa. A remuneração também é indivisível.

O segundo caso mais freqüente é o trabalho de um grupo de membros da família ampla, com pouca divisão do trabalho também mas com remuneração separada, em porcentagem de produto, para os casados. Todos os que trabalham moram na mesma propriedade. $\mathrm{O}$ pai toma as decisões mais importantes e é ele o integrado na sui- nocultura.

O fato de que os micro-produtores e a mais da metade dos pequenos estejam nestes dois últimos casos é significativo. Entre estes casos também encontram-se minoritariamente médios produtores. Se a contratação de mão de obra externa não tem uma relação de causalidade linear com a capitalização do estabelecimento nem decorre necessariamente dela, a relação entre ambos processos fica aqui evidente.

Mas a disponibilidade de trabalho familiar em abundância, sem necessidade de contratar mão de obra externa, também é um fator que permite a ampliação das atividades produtivas e pode, em certas circunstâncias, facilitar a via da capitalização. A falta de mão de obra na família é apontada por alguns agricultores como entrave para aumento da área de culturas e de escala na suinocultura. Ao mesmo tempo, a entrada em uma nova atividade é justificada como forma de maximizar as disponibilidades de mão de obra.

\footnotetext{
"Comecei a fumicultura para por as meninas para trabalhar. Elas estavam muito na folga com a mãe delas a cuidar um pouco dos porcos e resolvi que dava para aproveitar melhor com o fumo". (História de vida $\mathrm{n}^{\circ} 2$, julho de 1993).

A carência de mão de obra fa-
}

- ${ }^{9}$ Peão é a denominação que se dá em algumas regiões rurais brasileiras para empregados assalaria-

- dos sem maior qualificação, sejam permanentes ou temporários. Peãozinho é um diminutivo que - tem a ver com a idade dos sobrinhos (bem jovens). 
miliar é também fator de impulso para a modernização ou semimodernização das culturas. $\mathrm{O}$ uso maior de herbicidas e outros insumos modernos é apontado freqüentemente como induzido pela carência de mão de obra mais do que a mecanização, uma vez que esta, em níveis mínimos, já faz parte corrente da maior parte destes produtores que cultivam soja e milho.

A questão da divisão do trabalho nestes estabelecimentos indica a relevância da suinocultura no seu âmbito. É o próprio responsável pelo estabelecimento - o produtor integrado - que toca a criação, com a ajuda da mulher e/ou de um filho. Não são muitos os casos em que a mão de obra externa se ocupa da criação e nem mesmo aqueles em que um filho é o responsável. $\mathrm{O}$ mais freqüente é que trabalhem com o produtor. Em todos os casos, a suinocultura ocupa, além do trabalho de uma ou duas pessoas mais regularmente, horas avulsas da mão de obra em geral do estabelecimento: "todos quando precisa”.

Sua demanda em trabalho não é pequena, ao contrário do que se pode depreender da idéia corrente de que é complementar às culturas porque não concorre com elas nem em espaço nem em tempo que demanda. Isto é parcialmente verdadeiro para os produtores de pequena escala e mesmo assim em certas fases do ciclo produtivo sobretudo na terminação). Mas um pequeno aumento da escala já demanda um trabalho importante: os pequenos produtores dedicam em torno de quatro horas nos períodos normais, mas sempre adicionadas de passadas e tarefas a mais feitas por outro membro da família. Os médios também, mas já se encontram entre os que se dedicam perto de oito horas à suinocultura. Entre os grandes, estão os que dizem que a suinocultura, para ser rentável, necessita de um quase plantão permanente.

Grande parte dos estudos sobre os produtores rurais, sejam ou não integrados, tomam a composição da força de trabalho como variável fundamental para a estruturação da natureza do estabelecimento e, por conseqüência, para um qualificação do produtor seja como empresário ou capitalista, seja como trabalhador com terra ou seja ainda como uma das categorias intermediárias entre estas duas polares $^{10}$. Os agricultores, pelo menos estes aqui analisados, trazem uma representação a mais para esta questão: o que diferencia um empresário agrícola dos outros os agricultores em geral - é o fato de que ele não trabalha mais no campo, não despende esforço pessoal na atividade, afastou-se da produção como trabalhador para supervisioná-la, em fim, ele gere, não trabalha mais.
O fato se empregar trabalho assalariado ou não é um elemento menos central para esta percepção. Para exemplificar esta questão, a seguinte discussão foi suscitada após um encontro de suinocultores, com um grupo de seis produtores:

"Pergunta: O que vocês acharam do encontro?

Agricultor 1: O encontro não teve nada a ver para nós, foi um encontro de empresários e não de produtores, agricultores como nós.

Pergunta: Mas por que? Qual a diferença entre empresário e agricultor?

Agricultor 2: É fácil você perceber. O empresário não trabalha mais, virou burocrata, é capaz de ter esquecido de ajudar a porca a parir.

Agricultor 3: Nem vai querer se sujar e ficar fedendo...

Agricultor 1: Este pessoal aqui não é mais da atividade, eles sabem falar de índices mas não sabem mais o que é cuidar da criação.

Pergunta: Então empresários são os que têm empregados para fazer o trabalho do estabelecimento?

Agricultor 3: É o que não trabalha na roça porque empregado muita gente tem e não vira empresário.

Agricultor 4: Se o cara tem ajuda mas $\ldots \ldots \ldots$

\footnotetext{
- ${ }^{10} \mathrm{O}$ uso explícito ou implícito destas categorias é bastante usual nos estudos sobre agricultores e - agricultura. Apesar de designações marxistas, o seu uso é meramente classificatório, o que é mais - freqüente nos dias atuais do que seu emprego em interpretações essencialistas das concepções mar- xistas de classes e grupos sociais.
}

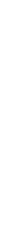




\section{Angela Duarte Damasceno Ferreira}

60

trabalha ele mesmo, é diferente, pode modernizar, fazer administração mas se ele mesmo põe a mão na massa é diferente."

A mesma diferenciação foi feita por outros agricultores, como se pode ver na fala abaixo (em que um grande agricultor se refere a outro):

"Você acha que se ele fosse empresário estava na roça a esta hora e voltava assim todo sujo? É esta a diferença: agricultor é agricultor porque trabalha na roça, nem mais nem menos" (História de vida $n^{\circ} 1$, junho de 1991)

Esta ética do trabalho e este apego ao métier é bastante interessante porque foi mencionada por pequenos produtores e também por grandes produtores familiares. É sem dúvida uma representação que encobre diferenças fundamentais entre os agricultores que trabalham mas que tem seu peso se pensarmos que estes agricultores - de todos os tipos - são agricultores familiares, ou seja, são na maioria os que estão presentes na propriedade, trabalham com membros de sua família no trabalho agrícola mesmo se também o supervisionam. Pode-se supor que, se esta representação dos agricultores encobre diferenças, revela, no entanto, outras: os empresários rurais ou grande proprietários que delegaram a gestão e a produção a terceiros e que são, freqüentemente, absenteístas, estão excluídos desta construção de identidade. agricultor integrado se articula com a construção do agricultor ideal para as agroindústrias: as tradicionais preferências das agroindústrias pelo trabalho familiar vão, atualmente, mais na direção da presença e trabalho do dono, com ou sem empregados, do que no sentido de uma exigência genérica de que apenas a família toque a produção.

A questão do agricultor e do empresário volta a surgir quando se analisa outro aspecto da organização dos estabelecimentos dos integrados que é a gestão. Alguns elementos do conjunto de procedimentos de gestão foram, centrando-se na atividade da suinocultura, que, como se viu, é importante para todos estes agricultores e prioritária para alguns..

O primeiro elemento analisado foi a composição dos custos de produção. Para os agricultores entrevistados, o que se gasta monetariamente compõe o seu custo, na sua maioria. Os gastos não monetários raramente são contabilizados, excetuando-se o uso do milho próprio que todos tomam em consideração. Isto quer dizer que o conjunto do trabalho familiar não remunerado e dos insumos secundários que vêm do próprio estabelecimento não são contabilizados.

Também são poucos os que prevêem um índice para cobrir a deteriorização das instalações. A maioria faz a este respeito referências pontuais e imediatas, o que não implica necessariamente na sua inclusão como elemento permanente de custo:

"Neste ano tive de reformar uma parte do teto da maternidade e foi um dinheirão. Ninguém me paga isto, tem de torcer para o preço compensar e cobrir." (Entrevista n ${ }^{\circ}$ 4, abril de 1991).

A respeito da composição do custo, há uma diferença visível entre os grandes produtores (tipos 4 e 5) e os outros: todos agricultores incluídos nestes tipos afirmaram controlar os custos seguindo as normas de alguma planilha técnica (seja da própria empresa integrante, seja a da EMBRAPA Empresa Brasileira de Pesquisa Agropecuária) e que, portanto, levavam todos os itens de custo em consideração. Mas mesmo assim, eles admitem que seria muito trabalhoso incluir tudo, porque difícil de mensurar o que não é custo monetário e que as planilhas técnicas não levam em conta, como certos insumos advindos do próprio estabelecimento e o trabalho intermitente de diferentes membros da família).

Um elemento atrelado a este é o controle destes custos. A maioria do agricultores entrevistados não mantém uma contabilidade dos gastos nem anota por escrito seus desembolsos em dinheiro. Todos guardam as notas de compra mas poucos se servem delas para controlar mesmos os gastos monetários, quanto menos os demais. As respostas foram neste sentido: "tentou mais desistiu porque acaba não fechando as contas no final"; "controla mais ou menos 
porque não dá tempo"; "confia na empresa que tem tudo anotado"; "resolveu não controlar para não ver que está no vermelho”. Entre os grandes produtores a maioria anota os gastos mas estima vagamente os custos não monetários.

Este traço claramente não empresarial dos agricultores integrados se refere à suinocultura integrada e não necessariamente à sua administração do estabelecimento como um todo. Pode-se supor que isto em parte se explica pelo fato de que se trata de uma atividade em que o capital de giro é menor, porque grande parte dos insumos é fornecida pela empresa para desconto no pagamento do produto, ao final do ciclo. Este fato, aliada à inexistência de preocupações de comercialização por parte dos agricultores, conduzem a uma menor preocupação com custo.

Embora esta explicação seja válida, ela não esgota o entendimento da questão. Na verdade, muitos destes agricultores repetem parte destas concepções nas atividades da lavoura. O que parece estar na base desta forma de gestão é, em primeiro lugar, uma certa percepção do trabalho familiar e a já mencionada hierarquia dos produtos do estabelecimento.

O trabalho não pago é naturalizado, sua inserção no processo de produção de um estabelecimento familiar é uma conseqüência natural de ser membro da família. Os produtores atualmente desnaturalizaram em grande parte o trabalho da família, porque o estudo já é largamente colocado como relevante e é uma alternativa para o uso do tempo dos filhos, o que ressalta o caráter social, ou melhor dizer, adquirido, do trabalho que eles realizam no estabelecimento. O migração de alguns filhos, ao mesmo tempo, ressalta este aspecto do trabalho dos que ficaram. Mas, paralelamente esta dimensão do natural permanece e influi na exclusão do trabalho familiar ou de uma parte dele da análise de custos. Além disto, aquele trabalho de todos, intermitente - que Tepicht ${ }^{11}$ chama de fundos indivisíveis do trabalho familiar- não é nunca contabilizado, como parte dos cuidados rotineiros com o criação ou o trabalho feminino doméstico e no terreiro mais próximo da casa familiar (o trabalho feminino é menos que contabilizado, porque freqüentemente aparece como nãotrabalho).

A desvalorização das plantações de subsistência, porque feitas com trabalho familiar e poucos ou nenhum insumo externo, pode ajudar a entender porque certos produtos usados como secundários na alimentação animal também não são contabilizados por grande parte dos agricultores.

Finalmente, há a própria concepção que estes agricultores têm sobre o lucro e que é tanto conseqüência como também motivo desta atitude em relação à contabilidade da atividade.

Se perguntados sobre o lucro da sua criação, dois terços deles não puderam precisar um percentual ou índice para as últimas vendas que haviam concluído, o que, obviamente, é fruto da dificuldade de conhecer e controlar os custos. Entre estes, a resposta mais freqüente foi no sentido de "não sabe mas dá prá viver". Entre os que responderam com índices, a maioria baseava-se em informações da empresa integrante. Outros frisaram que não tinham certeza mas que pareciam ter alcançado tal ou qual índice de lucratividade. Poucos-geralmente os maiores e que também eram os mais precisos na consideração dos custos - tinham um controle mais exato da sua lucratividade.

A concepção de lucro que se depreende da resposta de que "dá para viver" é sua assimilação à reposição das condições de reprodução social da família. Neste caso, importa para os agricultores ver em que medida a atividade permite que esta reprodução se realize e em que nível de qualidade de vida, o que relega a questão do controle dos custos e da contabilidade à segundo plano.

Neste sentido, é interessante observar as formas em que esta parcela de agricultores se exprime sobre o que significaria ter um estabelecimento mais lucrativo: "é

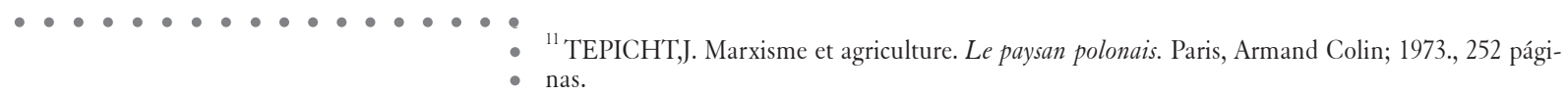


poder sair todos os anos de férias"; "não ter risco de não pagar empréstimos e perder a terra"; "ter reservas para agüentar numa crise", "poder diversificar menos e se concentrar em uma ou duas coisas"; "ter mais tempo para passear, ter menos trabalho". Esta percepção é predominante entre os micro e pequenos produtores e é referida por cerca da metade dos agricultores classificados na tipologia como médios.

Nos agricultores dos tipos 4 e 5 , sua percepção do lucro como excedente monetário obtido com a atividade produtiva e devendo ser reinvestido nesta atividade é a predominante. Assim suas observações mais freqüentes vão numa direção bem diferente do que as dos outros agricultores: "ter mais capital de giro próprio e dispensar empréstimos"; "estruturar bem a atividade para sair da integração e comercializar em melhores condições"; "ter sobras maiores para investimentos na melhoria da propriedade".

Pode-se assim dizer que as diferenciações entre os agricultores geram tipos também diferenciados de racionalidades de gestão da unidade produtiva. Se, segundo o discurso dos agricultores, o objetivo principal é, para todos, os rendimentos e o lucro, existe uma outra racionalidade, inerente à dimensão sócio-cultural dos agricultores, que age enquanto coadjuvante da razão econômica e instrumental. Esta racionalidade "outra" interfere na gestão do estabelecimento como um todo, inclusive na atividade contratualizada, interfere nas expectativas que os agricultores têm em relação ao contrato e nas representações que fazem dele.

\section{Conclusões}

Mostrou-se como o contrato de integração e o processo de modernização que acarreta não eliminou todas as características que se poderia chamar de camponesas ou de tradicionais dos estabelecimentos estudados, isto em três níveis de análise:

- Se foi enfatizada a idéia do contrato como relação social, também analisou-se de que forma a compreensão da estratégia de contratualização dos agricultores passa por fatores inerentes à dimensão interna de seus estabelecimentos, ou seja, pelas relações existentes no seu seio entre família, trabalho, atividades produtivas, tecnologia, racionalidade de gestão e projetos de vida que dão um sentido a este conjunto de fatores.

- O trabalho familiar representa o trabalho fundamental realizado nos estabelecimentos estudados. Nos ciclos da família em que há falta de trabalho da família, a utilização de insumos e máquinas pode suprir esta carência mas também o recurso a outras formas de trabalho. Neste sentido, são freqüentemente as necessidades da família que regulam as formas de trabalho utilizadas e o manejo dos produtos do estabelecimento. O pró- prio produto integrado não deixa de ser susceptível a estes fatores, embora em menor grau, dadas as determinações do contrato.

A este respeito, é importante ressaltar que os laços familiares podem se constituir numa forma de arregimentar e contratar mão de obra em estabelecimentos onde os membros da família nuclear só se ocupam da gestão do trabalho e que são mais próximos de modo de funcionamento de empresa.

- Os projetos dos agricultores, no que concerne especificamente a seus estabelecimentos e suas lógicas produtivas, apontam para uma busca de melhor qualidade da vida da família, principalmente no que se refere a quase totalidade dos agricultores que chamamos de micro e pequenos e à grande parte dos médios. Não deixam de fazer esforços consideráveis de investimento e valorizam principalmente os produtos para comércio. Mas a questão que aqui se coloca é a compreensão do sentido dos esforços realizados, o que não poderia ter sido logrado através de uma análise estritamente econômica.

Esta análise também reafirma a heterogeneidade dos agricultores familiares: o reconhecimento da importância da família no sentido de estruturar uma certa forma de funcionamento do estabelecimento agrícola não suplanta as diferenças fundamentais que separam agricultores entre os que con- 
seguiram se capitalizar e os que conseguem se reproduzir como agricultores buscando melhorar os patamares desta reprodução.

Finalmente, no que diz respeito à questão metodológica, demonstrou-se a utilidade dos métodos chamados quantitativos para um primeiro agrupamento dos agricultores. No entanto, foram ao mesmo tempo evidenciados seus limites e a necessidade de serem associados a métodos que possibilitem compreender os significados diferentes que a denominação genérica de agricultor familiar não permite supor. 